\title{
Fatty acid profiles of fermented soybean prepared by Bacillus subtilis and Rhizopus oligosporus
}

\section{Anittaya Kanghae, Prapassorn Damrongkool Eungwanichayapant, Ekachai Chukeatirote*}

School of Science, Mae Fah Luang University, Chiang Rai 57100, Thailand

*Corresponding author, E-mail: ekachai@mfu.ac.th

\begin{abstract}
There are various types of fermented soybean products in Asia including Natto (Japan), Jang (Korea), Kinema (India), and Thua Nao (Thailand). For these products, bacteria mostly belonging to the genus Bacillus (i.e., Bacillus subtilis) are used. This study was aimed to use a co-culture between B. subtilis and Rhizopus oligosporus in preparing the fermented soybean. Initially, the raw soybeans were washed, sterilized by autoclaving, and inoculated with these inocula; for this, three different ratios between B. subtilis and $R$. oligosporus were used (100:0, 50:50, and 0:100). The fermentation was carried out at $30^{\circ} \mathrm{C}$ for 3 days, and fatty acid concentration was determined. Results showed that palmitic, stearic, oleic, linoleic, and eicosanoic acids were present in the fermented soybeans products. The major fatty acids present in all samples were oleic and linoleic, ranging between 30.49 to 34.07 and 50.35 to $53.72 \%$ of total fatty acids, respectively.
\end{abstract}

Key words: Bacillus, fatty acid, fermented soybean, Rhizopus.

Abbreviations: CNF, cooked non-fermented soybeans; FAMEs; fatty acid methyl esters.

\section{Introduction}

Fermentation of soybean is generally considered as one of the successful methods helping in preserving and prolonging shelf life of soybean. In addition, after the fermentation soybean exhibits distinct characteristics (i.e., flavor and aroma) and, in some cases, becomes popular once accepted by the consumers. Natto is probably the best example of this case. Since its origin, Natto, which is produced using a pure starter culture of Bacillus subtilis (natto strain), has gained popularity and is widely known and consumed by people around the world (Kiuchi, Watanabe 2004). The Natto industry is increasing; in 2015, it was estimated that approximately 750 tonnes of Natto were produced with a value around 4 million US dollars (FAO 2016). There are other fermented soybean products, traditionally produced and only consumed by local people, which include Cheonggukjang of Korea, Douchi of China, Kinema of Nepal and India, and Thua Nao of Thailand. These products are similar in terms of raw materials used and the production process (Sarkar, Nout 2015). It should be noted, however that, unlike Natto, these fermented soybean products have not gained much attention and are still produced by artisanal techniques (i.e., produced at the household scale and using natural microbial starter cultures).

During soybean fermentation, it is expected that soy substrates are hydrolysed by many degrading microbial enzymes. Due to the protein-rich nature of soy, proteolysis is typically considered as a key process of soybean fermentation, which has been studied by many researchers (Omafurbe et al. 2000; Visessanguan et al. 2005; Hu et al. 2010). In contrast, lipolysis has not gained much attention, although the soybean substrate is composed of around $20 \%$ of fat. Lipids are degraded into fatty acids resulting in development of some volatiles including alcohols, aldehydes and ketones in some foods (Visessanguan et al. 2006; Gambacorta et al. 2009). Similarly, lipolysis may be one of the key mechanisms occurring during the soybean fermentation. Unfortunately, there are only a few studies dealing with lipid profiles in fermented soybean products (de Reu et al. 1994; Sarkar et al. 1996; Feng et al. 2014). As part of the programme to develop a production process by utilization of fermented soybean, the present study was carried out to determine the lipid composition of the fermented soybeans prepared by a co-culture between the bacterium B. subtilis and the fungus Rhizopus oligosporus.

\section{Materials and methods}

\section{Microbial cultures}

The bacterium Bacillus subtilis strain TN51 was previously isolated from Thai Thua Nao (Dajanta et al. 2009). For inoculum preparation, the bacteria were grown in nutrient broth at $37^{\circ} \mathrm{C}$ for $24 \mathrm{~h}$. The cells were then harvested, resuspended in sterile distilled water and adjusted to

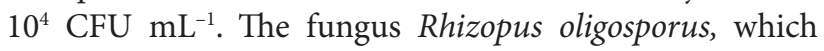
originated from Indonesian Tempeh, was obtained from the Agricultural Research Service Culture Collection, Bacterial Foodborne Pathogens and Mycology Research 
Unit National Center for Agricultural Utilization Research (USA). For preparation as a starter culture, the fungus was maintained on potato dextrose agar at $30^{\circ} \mathrm{C}$ for 3 to 4 days. The spores were then harvested, resuspended in sterile distilled water and adjusted to $10^{4} \mathrm{CFU} \mathrm{mL}^{-1}$.

\section{Soybean fermentation}

Soybeans were washed and soaked in water for $16 \mathrm{~h}$ at room temperature. Prior to fermentation, two different methods were employed to prepare cooked non-fermented soybeans (CNF). For conventional fermentation, soaked soybeans were cooked by boiling for $3 \mathrm{~h}(\mathrm{CNF} 1)$ and left to ferment by naturally occurring microbes at $30{ }^{\circ} \mathrm{C}$ for 72 h (TNM). In contrast, for inoculum fermentation, soaked soybeans were autoclaved at $121^{\circ} \mathrm{C}$ for $40 \mathrm{~min}$ (CNF2). The fermentation was then prepared using microbial inocula [ $10^{4} \mathrm{CFU}$ (or conidia) $\mathrm{g}^{-1}$ of the autoclaved soybeans]. Three treatments with different ratios between $B$. subtilis and $R$. oligosporus were prepared as follows: (i) 100:0 (TNB), (ii) 50:50 (TNBR), and (iii) 0:100 (TNR). After that, the soybeans were incubated at $30^{\circ} \mathrm{C}$ for $72 \mathrm{~h}$.

\section{Fatty acid composition analysis}

Initially, forty grams of fermented soybeans were ground into fine powder. For lipid extraction, the sample powder was packed in a cellulose thimble inside the extraction chamber of the Soxhlet unit. Pure n-hexane $(280 \mathrm{~mL})$ was used to extract the lipid by refluxing at $70{ }^{\circ} \mathrm{C}$ for $2 \mathrm{~h}$. The remaining hexane solvent was then removed under vacuum at $70{ }^{\circ} \mathrm{C}$ and the extracted lipid samples were kept at $4{ }^{\circ} \mathrm{C}$ until further use.

For fatty acid analysis, fatty acid methyl esters (FAMEs) were prepared as described by Nielsen (2010). In brief, the extracted lipids $(30 \mathrm{mg}$ ) were mixed with $1 \mathrm{~mL}$ of $0.5 \%$ $\mathrm{NaOH}$ in methanol and incubated at $60{ }^{\circ} \mathrm{C}$ for $20 \mathrm{~min}$. After cooling to room temperature, $1 \mathrm{~mL}$ of $\mathrm{n}$-hexane was added and vortexed for $1 \mathrm{~min}$. Subsequently, $400 \mu \mathrm{L}$ of sterile double distilled $\mathrm{H}_{2} \mathrm{O}$ were added and mixed by vortexing for $30 \mathrm{~s}$. The hexane layer was then transferred to a vial containing a small amount of sodium sulfate (for at least $15 \mathrm{~min}$ ). The hexane phase was finally filtered through a $0.25 \mu \mathrm{m}$-nylon syringe filter and stored at $4{ }^{\circ} \mathrm{C}$ prior to analysis.

An Agilent Technologies 6890N gas chromatograph equipped with an Agilent 5973N mass spectrometer system was used for fatty acid analysis profiling. Operating conditions were as follows: the column was a HP-5 MS Agilent capillary column $(30 \mathrm{~m} \times 0.25 \mathrm{~mm}$ i.d., $0.25 \mu \mathrm{m}$ film thickness); helium was the carrier gas at a constant flow rate of $1 \mathrm{~mL} \mathrm{~min}^{-1}$; the GC injector was set up in a splitless mode; the injector and detector temperature was set at 250 ${ }^{\circ} \mathrm{C}$; the oven temperature was programmed starting at 120 ${ }^{\circ} \mathrm{C}$ for $2 \mathrm{~min}$, then increasing to $250{ }^{\circ} \mathrm{C}$ with the rate of 10 ${ }^{\circ} \mathrm{C} \mathrm{min}^{-1}$. To identify individual FAMEs from the samples, an Agilent $5973 \mathrm{~N}$ mass spectrometer was used in the scan mode with the mass range of 30 to $400 \mathrm{amu}$ and electron impact ionization mode with an ionization voltage of 70 $\mathrm{eV}$. The ion source temperature was $230^{\circ} \mathrm{C}$ and the GC-MS transfer line was set at $280^{\circ} \mathrm{C}$. The results obtained were then recorded and expressed as relative area percentage.

\section{Results and discussion}

As part of a programme to improve the fermentation process of soybean using co-culture between B. subtilis and $R$. oligosporus, this study was focused on fatty acid profiles, which would be useful as food compositional data. In this analysis, total fatty acid content of the samples were extracted, prepared as FAMEs, and subjected to the GC for identification. A representative GC chromatogram of the FAMEs of the fermented samples is depicted in Fig. 1. In total, five fatty acids were identified using the MS analysis. Based on this analysis, there was an additional compound octadecenamide (or oleamide), identified in peak no. 6. This compound is an amide of oleic fatty acid, and thus was excluded from further analysis.

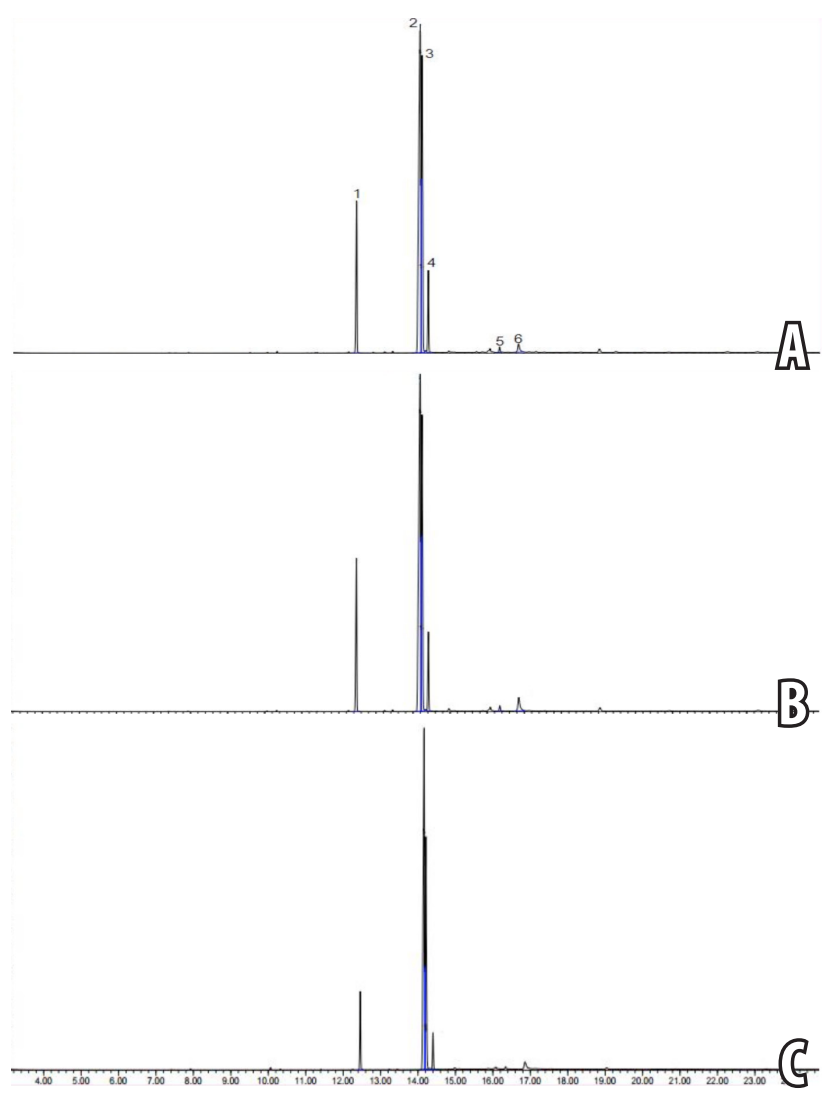

Fig. 1. Representative GC chromatogram of fatty acid methyl esters (FAMEs) from the lipid extracts of the autoclaved soybean (A), the fermented soybean prepared by B. subtilis (B), and the fermented soybean prepared by B. subtilis and R. oligosporus (C). Peak identification: 1, palmitic acid (C16:0); 2, linoleic acid (C18:2, $\omega 6)$; 3, oleic acid $(\mathrm{C} 18: 1, \omega 9)$; 4, stearic acid (C18:0); 5, eicosanoic acid (C20:1); 6, 9(Z)-octadecenamide $\left(\mathrm{C}_{18} \mathrm{H}_{35} \mathrm{NO}\right)$. 
Table 1. Fatty acid profiles of cooked non-fermented soybean (CNF) and fermented soybean. The data shown are means and SD. Means in a row with different letters are significantly different $(p<0.05)$. SFA, saturated fatty acid; UNSAT, unsaturated fatty acid; CNF1, boiled soybean; CNF2, autoclaved soybean; TNM, naturally fermented soybean TNB, fermented soybean by B. subtilis; TNR, fermented soybean by R. oligosporus; TNBR, fermented soybean by a co-culture of B. subtilis and R. oligosporus

\begin{tabular}{lcccccc} 
Fatty acids & CNF1 & CNF2 & TNM & TNB & TNR & TNBR \\
Palmitic acid (16:0) & $12.15 \pm 0.10 \mathrm{a}$ & $11.96 \pm 0.02 \mathrm{~b}$ & $11.99 \pm 0.06 \mathrm{~b}$ & $11.87 \pm 0.08 \mathrm{~b}$ & $9.67 \pm 0.04 \mathrm{c}$ & $8.34 \pm 0.07 \mathrm{~d}$ \\
\hline Stearic acid (18:0) & $5.72 \pm 0.07 \mathrm{a}$ & $5.78 \pm 0.03 \mathrm{a}$ & $5.82 \pm 0.00 \mathrm{a}$ & $5.75 \pm 0.06 \mathrm{a}$ & $4.62 \pm 0.07 \mathrm{~b}$ & $3.87 \pm 0.14 \mathrm{c}$ \\
Oleic acid (18:1) & $31.78 \pm 0.10 \mathrm{c}$ & $30.61 \pm 0.18 \mathrm{~d}$ & $30.49 \pm 0.11 \mathrm{~d}$ & $30.70 \pm 0.25 \mathrm{~d}$ & $32.76 \pm 0.11 \mathrm{~b}$ & $34.07 \pm 0.09 \mathrm{a}$ \\
Linoleic acid (18:2) & $50.35 \pm 0.08 \mathrm{~d}$ & $51.18 \pm 0.16 \mathrm{c}$ & $51.23 \pm 0.10 \mathrm{c}$ & $51.22 \pm 0.11 \mathrm{c}$ & $52.95 \pm 0.14 \mathrm{~b}$ & $53.72 \pm 0.22 \mathrm{a}$ \\
Eicosanoic acid (20:1) & $0.00 \pm 0.00 \mathrm{c}$ & $0.46 \pm 0.01 \mathrm{~b}$ & $0.47 \pm 0.00 \mathrm{a}$ & $0.47 \pm 0.00 \mathrm{a}$ & $0.00 \pm 0.00 \mathrm{c}$ & $0.00 \pm 0.00 \mathrm{c}$ \\
\hline SFA & $17.87 \pm 0.03 \mathrm{a}$ & $17.74 \pm 0.04 \mathrm{ab}$ & $17.81 \pm 0.05 \mathrm{a}$ & $17.62 \pm 0.14 \mathrm{~b}$ & $14.29 \pm 0.03 \mathrm{c}$ & $12.21 \pm 0.14 \mathrm{~d}$ \\
UNSAT & $82.13 \pm 0.03 \mathrm{~d}$ & $82.25 \pm 0.04 \mathrm{~cd}$ & $82.19 \pm 0.05 \mathrm{~d}$ & $82.39 \pm 0.14 \mathrm{c}$ & $85.71 \pm 0.03 \mathrm{~b}$ & $87.79 \pm 0.14 \mathrm{a}$ \\
UNSAT/SFA & $4.60 \pm 0.01 \mathrm{c}$ & $4.63 \pm 0.02 \mathrm{c}$ & $4.62 \pm 0.04 \mathrm{c}$ & $4.67 \pm 0.04 \mathrm{c}$ & $6.00 \pm 0.02 \mathrm{~b}$ & $7.19 \pm 0.09 \mathrm{a}$
\end{tabular}

As shown in Table 1, five fatty acids were identified in the CNF and fermented samples. These included two saturated fatty acids [palmitic (16:0) and stearic (18:0)], and three unsaturated fatty acids [oleic (18:1), linoleic (18:2), and eicosanoic (20:1)]. In general, the fatty acid composition profile was very similar between CNF samples. These amounts of fatty acids can be considered as the starting composition of soybean raw material prior to fermentation. It should be noted, however, that there were some slight differences in amounts of the three fatty acids: palimitic, oleic, and linoleic. Also the presence of eicosanoic acid was detected in the CNF2 sample, but not in the CNF1 sample. These differences may have arisen from the cooking process used (i.e., boiling and autoclaving for the CNF1 and $\mathrm{CNF} 2$, respectively), as heat treatment significantly affects fatty acid levels (Zilic et al. 2010; Ouazib et al. 2015).

The CNF soybean samples were then fermented with different starter cultures. For this, the CNF1 was fermented by naturally occurring microorganisms yielding the TNM sample. The CNF2 samples were inoculated with $B$. subtilis, R. oligosporus, and a co-culture of B. subtilis and $R$. oligosporus, resulting in the TNB, TNR, and TNBR samples, respectively. As illustrated in Table 1, the fermentation by different starter cultures seemed to affect the fatty acid contents. TNB and TNM samples had a similar fatty acid composition profile. Similarity was also observed in fatty acid concentrations with the starter soybean substrates (CNF1 and TNM; CNF2 and TNB). This suggests that the bacterial starter culture might have little (or no) effect on fatty acid concentration. This is in agreement with previous research describing that most Bacillus species do not have (or slightly have) lipase enzyme activity (Aderibigbe, Odunfa, 1990; Omafuvbe et al. 2000; Chukeatirote et al. 2006).

In contrast, the use of the fungus $R$. oligosporus in preparing fermented soybean products (TNR and TNBR) resulted in a dramatic change of fatty acid composition. In general, there was a shift from the saturated fatty acids (16:0 and 18:0) to the unsaturated fatty acids (18:1 and 18:2) in the composition. The fungal inoculation also caused disappearance of the eicosanoic acid (20:1) which was initially present in the starter CNF2 substrate. Interestingly, our data showed that the fungal inoculation as a ( $\left.\mathrm{CO}^{-}\right)$ starter culture in soybean fermentation contributed to an increase in concentration of unsaturated fatty acids. Also, the ratio between the total unsaturated and saturated fatty acids was higher in the TNR and TNBR samples. The fungus $R$. oligosporus is well known for its ability to produce the lipase enzymes (ul-Haq et al. 2002; Iftikhar et al. 2010). It is therefore obvious that a significant shift in fatty acid contents found in the fermented soybean products was due to effect of fungal lipase enzymes.

Fermentation of soybeans led to a shift in fatty acid profiles. For example, there was an increase of the levels of the unsaturated fatty acids, as shown in the present study (Table 1). Fermented soybean products especially those prepared by the fungus $R$. oligosporus, are rich in oleic and linoleic fatty acids. Many previous studies have shown that fatty acid contents play an important role in the flavor of the food products (Larick, Turner, 1990; Ha, Lindsay, 1991; Toldra, Flores 1998). Soybeans in particular are known to contain fair amounts of lipids, and in general are considered 'undesirable' by most consumers in the western countries. These undesirable features include characters like as beany, green, grassy, painty, astringent, and bitter, which have been shown to be associated with flavours arising from the oxidation of polyunsaturated lipids by lipoxygenases of soybeans (Yang et al 2015). Further work is needed to identify the key components (including the fatty acid components) to ensure optimal sensory characteristics.

\section{Conclusions}

This present study described the fatty acid composition of fermented soybean products prepared by selected starter cultures of (i) B. subtilis, (ii) R. oligosporus, and (iii) a coculture B. subtilis and $R$. oligosporus. In general, it was found that there was a change in fatty acid content of the fermented products studied. Interestingly, the use of the fungal starter culture (i.e., Rhizopus as shown in this study) 
appeared to be a key factor causing a shift in the fatty acid profiles. Our result is preliminary and can be useful as a reference for food compositional data, and further work on understanding of lipolysis of fermented soybeans should be undertaken.

\section{Acknowledgements}

The authors gratefully acknowledge the Asia Research Centre, Chulalongkorn University (no. 005/2559), and Mae Fah Luang University for their financial support.

\section{References}

Aderibigbe E.Y., Odunfa S.A. 1990. Growth and extracellular enzyme production by strains of Bacillus species isolated from fermenting locust bean "iru”. J. Appl. Bacteriol. 69: 662-672.

Chukeatirote E., Chainun C., Siengsubchart A., Moukamnerd C., Chantawannakul P., Lumyong S., Boontim N., Thakang P. 2006. Microbiological and biochemical changes in Thua nao fermentation. Res. J. Microbiol. 1: 38-44.

Dajanta K., Wongkham S., Thirach P., Baophoeng P., Apichartsrangkoon A., Santithum P., Chukeatirote E. 2009. Comparative study of proteolytic activity of proteaseproducing bacteria isolated from thua nao. Maejo Int. J. Sci. Technol. 3: 269-276.

de Reu J.C., Ramdaras D., Rombouts F.M., Nout M.J.R. 1994. Changes in soya bean lipids during tempe fermentation. Food Chem. 50: 171-175.

FAO. 2016. Discussion paper on the development of a regional standard for Natto. Joint FAO/WHO Food Standards Programme, Delhi, India, 26 - 30 September 2016.

Feng Y., Chen Z., Liu N., Zhao H., Cui C., Zhao M. 2014. Changes in fatty acid composition and lipid profile during koji fermentation and their relationships with soy sauce flavour. Food Chem. 158: 438-444.

Gambacorta G., Sinigaglia M., Schena A., Baiano A., Lamacchia C., Pati S., La Notte E. 2009. Changes in free fatty acid and diacylglycerol compounds in short ripening dry-cured sausage. J. Food Lip. 16: 1-18.

Ha J.K., Lindsay R.C. 1991. Volatile branched-chain fatty acids and phenolic compounds in aged Italian cheese flavors. J. Food Sci. 56: 1241-1247.

Hu Y., Ge C., Yuan W., Zhu R., Zhang W., Du L., Xue J. 2010. Characterization of fermented black soybean natto inoculated with Bacillus natto during fermentation. J. Sci. Food Agric. 90: 1194-1202.

Iftikhar T., Niaz M., Zia M.A., ul Haq I. 2010. Production of extracellular lipases by Rhizopus oligosporus in a stirred fermentor. Braz. J. Microbiol. 41: 1124-1132.

Kiuchi K., Watanabe S. 2004. Industrialization of Japanese natto. In: Steinkraus K.H. (ed) Industrialization of Indigenous Fermented Foods.Marcel Dekker, New York, pp. 193-246.

Larick D.K., Turner, B.E. 1990. Flavor characteristics of forageand grain-fed beef as influenced by phospholipid and fatty acid compositional differences. J. Food Sci. 55: 312-317.

Nielsen S.S. 2010. Food Analysis Laboratory Manual. $2^{\text {nd }}$ Ed. Springer, New York.

Omafuvbe B., Shonukan O., Abiose S. 2000. Microbiological and biochemical changes in the traditional fermentation of soybean for "soy-daddawa" - Nigerian food condiment. Food Microbiol. 17: 469-474.

Ouazib M., Nadia M., Oomah B.D., Zaidia F., Wanasundarae J.P.D. 2015. Effect of heat processing and germination on nutritional parameters and functional properties of chickpea (Cicer arietinum L.) from Algeria. J. Food Leg. 28: 1-8.

Sarkar P.K., Jones L.J., Gore W., Craven G.S., Somerset S.M. 1996. Changes in soya bean lipid profiles during Kinema production. J. Sci. Food Agric. 71: 321-328.

Sarkar P.K., Nout M.J.R. 2015. Indigenous Foods Involving Alkaline Fermentation. CRC Press, Boca Raton.

Toldra F., Flores M. 1998. The role of muscle proteases and lipases in flavor development during the processing of dry-cured ham. Crit. Rev. Food Sci. Nutr. 38: 331-352.

ul Haq I., Idrees S., Rajoka M.I. 2002. Production of lipases by Rhizopus oligosporous by solid-state fermentation. Proc. Biochem. 37: 637-641.

Visessanguan W., Benjakul S., Potachareon W., Panya A., Riebroy S. 2005. Accelerated proteolysis of soy proteins during fermentation of Thua-Nao inoculated with Bacillus subtilis. J. Food Biochem. 29: 349-366.

Visessanguan W., Benjakul S., Riebroy S., Yarchai M., Tapingkae W. 2006. Changes in lipid composition and fatty acid profile of Nham, a Thai fermented pork sausage, during fermentation. Food Chem. 94: 580-588.

Yang A, Smyth H, Chaliha M, James A. 2015. Sensory quality of soymilk and tofu from soybeans lacking lipoxygenases. Food Sci. Nutr. 4: 207-215.

Zilic S., Sobajic S., Mladenovic-Drinic S., Kresovic B., Vasic M. 2010. Effects of heat processing on soya bean fatty acids content and the lipoxygenase activity. J. Agric. Sci. 55: 55-64. 